\title{
A review and guide to creating patient specific 3D printed anatomical models from MRI for benign gynecologic surgery
}

\author{
Teresa E. Flaxman ${ }^{1,2^{*}}$ D, Carly M. Cooke ${ }^{2}$, Olivier X. Miguel ${ }^{1,3}$, Adnan M. Sheikh ${ }^{1,3,4}$ and Sukhbir S. Singh ${ }^{1,2,5}$
}

\begin{abstract}
Background: Patient specific three-dimensional (3D) models can be derived from two-dimensional medical images, such as magnetic resonance (MR) images. 3D models have been shown to improve anatomical comprehension by providing more accurate assessments of anatomical volumes and better perspectives of structural orientations relative to adjacent structures. The clinical benefit of using patient specific 3D printed models have been highlighted in the fields of orthopaedics, cardiothoracics, and neurosurgery for the purpose of pre-surgical planning. However, reports on the clinical use of 3D printed models in the field of gynecology are limited.

Main text: This article aims to provide a brief overview of the principles of 3D printing and the steps required to derive patient-specific, anatomically accurate 3D printed models of gynecologic anatomy from MR images. Examples of 3D printed models for uterine fibroids and endometriosis are presented as well as a discussion on the barriers to clinical uptake and the future directions for 3D printing in the field of gynecological surgery.

Conclusion: Successful gynecologic surgery requires a thorough understanding of the patient's anatomy and burden of disease. Future use of patient specific 3D printed models is encouraged so the clinical benefit can be better understood and evidence to support their use in standard of care can be provided.
\end{abstract}

Keywords: MRI, Gynecology, Myomectomy, Endometriosis, 3D printing, Surgical planning, Barriers of use

\section{Background}

Magnetic resonance imaging (MRI) and ultrasound (US) are the first lines of investigation for the diagnosis and monitoring of pelvic pathologies [1]. MRI and US are also used for pre-surgical planning of complex cases because they help a surgeon to visualize the patient's anatomy, and location and extent of the disease [1]. Using medical imaging for pre-surgical planning of complex cases has been shown to reduce surgical complications and improve patient outcomes [2, 3]. However, for

\footnotetext{
* Correspondence: tflaxman@ohri.ca

'Department of Clinical Epidemiology, Ottawa Hospital Research Institute, 1967 Riverside Dr, 7th Floor, Ottawa, ON K1H7W9, Canada

${ }^{2}$ Department of Obstetrics and Gynecology, Faculty of Medicine, University of Ottawa, Ottawa, ON, Canada

Full list of author information is available at the end of the article
}

surgeons not experienced in reading 2D medical images, such as MRI and US, it can be difficult to appreciate complex anatomical structures and pathology in a way that can be applied to surgery [4].

Recent technological advancements in imaging have made it possible to generate three-dimensional (3D) constructs from two-dimensional (2D) images. By using specialized software, 2D medical images such as MRI, can be converted to 3D digital models. Rendering of 2D images to 3D digital models has been shown to significantly improve anatomical comprehension by providing more accurate assessments of anatomical volumes $[5,6]$, better perspective of structural orientations relative to adjacent structures [7], and improved visualization as transparency and colors can be modified to suit the user's needs.

\section{$\triangle B M C$}

(c) The Author(s). 2021 Open Access This article is licensed under a Creative Commons Attribution 4.0 International License, which permits use, sharing, adaptation, distribution and reproduction in any medium or format, as long as you give appropriate credit to the original author(s) and the source, provide a link to the Creative Commons licence, and indicate if changes were made. The images or other third party material in this article are included in the article's Creative Commons licence, unless indicated otherwise in a credit line to the material. If material is not included in the article's Creative Commons licence and your intended use is not permitted by statutory regulation or exceeds the permitted use, you will need to obtain permission directly from the copyright holder. To view a copy of this licence, visit http://creativecommons.org/licenses/by/4.0/ The Creative Commons Public Domain Dedication waiver (http://creativecommons.org/publicdomain/zero/1.0/) applies to the data made available in this article, unless otherwise stated in a credit line to the data. 
Furthermore, these 3D digital models can be converted into tangible, physical models by way of $3 \mathrm{D}$ printing [ 8 , 9]. Rather than 3D visualization where a volumetric model is viewed on a 2D computer screen, a 3D printed model can provide a real indication of depth and tactile feedback, thus allowing surgeons to develop a clearer understanding of surgical anatomy $[10,11]$. With a better visualization of disease location relative to adjacent organs, surgeons utilising 3D printed models for preoperative planning have been shown to have greater surgical outcomes including, decreased operative time [1214], blood loss [12, 13], and incision length [13].

The clinical benefits of using patient-specific 3D printed models for pre-surgical planning has been highlighted in the fields of orthopaedics [15], cardiothoracics $[16,17]$, and neurosurgery [18]. However, reports on the clinical use of 3D models in the field of gynecology are limited [19]. In this report, we will provide an overview of the principles of 3D printing and the steps required to derive patient-specific, anatomically accurate 3D printed models from MRI. We will then describe the application of 3D printed models for preoperative planning for two benign gynecologic conditions: uterine fibroids and endometriosis, and discuss barriers to clinical update and future directions for 3D printing in gynecology.

\section{D Printing}

\section{Basic principles}

Three-dimensional (3D) printing, also known as additive manufacturing, is a process used to create a $3 \mathrm{D}$ object by adding material in a layer-by-layer process. This technology can be used to rapidly manufacture objects with complex shapes, at a fraction of the cost compared to traditional manufacturing methods [20]. Due to the reduced manufacturing costs of 3D printers and improved printing precision and speed, the industry has recently exploded, allowing for major advances in many industries including the medical field [21]. Popular medical applications include hearing aids, prosthetic limbs, surgical guides and implants, and detailed models of organs, bones, and blood cells, which can be printed in a variety of materials including polymers, metal, and ceramics, depending on the application [22, 23].

Several technologies have been established to create 3D printed products. These include vat photopolymerization, directed energy deposition, binder and material jetting, powder bed fusion, sheet lamination, and material extrusion (MEX), whereby MEX is the most common technique. The main considerations when choosing the type of 3D printing to use depends on the application of manufactured parts, machine cost, speed of printing, multi-material capabilities (or single material), and types of materials available.
To prepare a product for 3D printing a 3D digital object is needed because when printing, each layer contains a cross-section of the 3D object which are computed from the digital representation. To create a 3D digital object, a computer-aided design (CAD) software is required. Like the different printers and materials available, there are several options including licenced software (e.g. Materialise Mimics) and open-source applications (e.g. MITK Workbench, 3D Slicer), which depends on the users needs and functionality.

\section{General workflow for applications in medical radiology}

In order to produce a patient specific and anatomically accurate 3D printed model, a high-resolution volumetric dataset is first required. Such datasets are typically stored as Digital Imaging and Communications in Medicine (DICOM) files. These files contain information about the medical image such as modality (type of imaging), contrast/gray values (in the form of $2 \mathrm{D}$ or $3 \mathrm{D}$ matrices), spacing between slices, spatial resolution, and anatomical orientation [24]. Volumetric DICOM data can be acquired from MRI, US, or computed tomography $(\mathrm{CT})$. From this, a labelling process called segmentation is used to identify and isolate anatomy of interest. Segmentation can be done automatically using algorithms such as thresholding, edge detection, and region growing, or manually by essentially tracing anatomy of interest on each image slice. Most often, segmentation requires a semi-automatic approach whereby a combination of algorithms are used and manually verified [16]. Unfortunately, a reliance on manual or semi-automatic segmentation requires expertise and a significant time commitment on the part of the user.

The labels of the segmented DICOM images are then converted to 3D digital models using specialized software and then are saved in a format used for the 3D printing process such as stereolithography (STL), OBJect (OBJ), additive manufacturing file (AMF), or 3D manufacturing format (3MF). STL is the most commonly used format but cannot store color, material, or texture information and requires additional software to do so. The file type will depend on the software and printers being used to create the model. In general, 3D printing file types describe the surface geometry of a 3D object which contains information such as spatial position, scale, and orientation. You can have more than one 3D object within a 3D printing file, which is useful when including multiple anatomical structures in a model. These files are then recognized by the 3D printer's supporting software. Here, the user can specify if 3D objects are to be printed individually or together, what colours the objects are to be printed as (if the file type and printer allows), and optimize the printing parameters to minimize material use and printing time. Printing times can vary 
depending on printer type, resolution, number of colours and materials used. After printing is complete, any support structure that was required to stabilize the model during the print is removed.

\section{D printing from MRI in gynecology}

Our institution's approach for deriving patient specific 3D printed anatomical models for applications in benign gynecology is described here. De-identified crosssectional images from MRI post gadolinium (with additional $2 \mathrm{~mm}$ T2 weighted isometric sequenced images acquired for $3 \mathrm{D}$ printing purposes) are exported in DICOM format. DICOM files are imported into Materialise Mimics 20.0 (Materialise, Leuven, Belgium) software where relevant gynecologic structures and patient anatomy are segmented (i.e. separated) semiautomatically under the supervision of our teams' fellowship-trained radiologists. We use a combination of signal thresholding, region growing and mask splitting algorithms to create basic masks (i.e. define overlapping objects) of anatomy of interest. Manual slice edits with interpolation are then conducted with direct planimetry to ensure accuracy of masks.

Once segmentation is complete, the $2 \mathrm{D}$ images are then converted to $3 \mathrm{D}$ objects to create a $3 \mathrm{D}$ digital model. Since we are doing multi-organ segmentation, we are dealing with multiple 3D objects with each 3D object being a different anatomical structure of interest. Each 3D object is exported to a separate STL file and then prepared for 3D printing via a computer-aided design (CAD) software 3-Matic (Materialise, Leuven, Belgium). The CAD process involves operations such as wrapping, smoothing and boolean operations (i.e. union, subtraction and intersection). The boolean subtraction operation is used to remove intersecting geometry of multiple 3D objects. For example, the endometrium model is subtracted from the uterus creating a cavity (i.e. negative space) in the uterus model. This is important to prevent unwanted overlapped material deposition during multi-material 3D printing.

The final digital model is then exported as multiple STL files and imported as an assembly into GrabCAD Print software (Stratasys, Inc., Eden Prarie, MN) for printing using a material jetting printer called the Connex 3 Objet 500 3D printer (Stratasys, Inc., Eden Prairie, $\mathrm{MN}$ ). Our models are printed using a combination of transparent and opaque material (Vero line, Stratasys, Inc.) based on the gynecologist's preference. For example, pathologic lesions or tissue of interest are printed in a bright opaque coloured material to maximize visualization in comparison to non-diseased anatomy printed in translucent clear material.

Figure 1 provides a typical workflow for creating anatomical models from DICOM files.

\section{Application of 3D printing in benign gynecology Uterine fibroids}

Uterine fibroids are common gynecological tumors affecting up to $80 \%$ of women by age 50 worldwide [25]. Although benign, nearly half of these women are symptomatic and experience a significant impact on their quality of life (i.e. heavy menstrual bleeding, dysmenorrhea, chronic pelvic pain, obstructions of adjacent organs, bulk symptoms, and infertility) and require intervention [25-30]. For women with uterine fibroids wishing to preserve their uterus and their fertility, best practice guidelines recommend conservative approaches including medical, surgical or interventional. Myomectomy is the surgical approach to removing fibroids [25], however, complications such as blood transfusion, injury to adjacent organs (bladder, bowel), endometrial perforation, and conversion to hysterectomy can occur in 2$35 \%$ of cases [31-33] because of the extent/complexity of disease. Consequently, patients can experience persistent symptoms and require additional surgery in $25-50 \%$ of cases [25], and 30\% of women may still experience infertility after surgical intervention [31].

3D printing is a novel approach for surgical planning of myomectomy or hysterectomy in uterine fibroids as a complementary tool beyond classic 2D imaging modalities. The application of patient-specific 3D printed anatomical models for pre-surgical planning of complex myomectomies has been previously described by our group [34, 35]. Figures 1, 2 and 3 provide examples of our 3D uterine models depicting multiple fibroids. Figure 2 also shows concurrent presence of adenomyosis printed in purple. In our experience, 3D printed models helped surgeons to assess the relationship of the uterine fibroids with surrounding anatomical structures, especially the endometrium and surrounding myometrium. This additional knowledge optimized their excisional course which in turn, minimized allotted surgical time and their perception of estimated blood loss, as well as helped to preserve integrity of the endometrial lining.

Our positive experience of using 3D models for presurgical planning and intra-operative reference aligns with previous reports by Aluwee and colleagues [7, 36], who used 3D rendered images and models from MRI for pre-surgical planning. In 10 myomectomy cases, the use of $3 \mathrm{D}$ rendered images significantly reduced the surgeon's time to complete a pre-surgical plan and increased the surgeon's accuracy of the pre-operative assessment of the disease complexity [7]. In cases of endometrial cancer requiring hysterectomy, surgeons report a positive experience using to models for presurgical planning as well as patient education [36]. Similarly, Mackey et al. implemented a patient-specific 


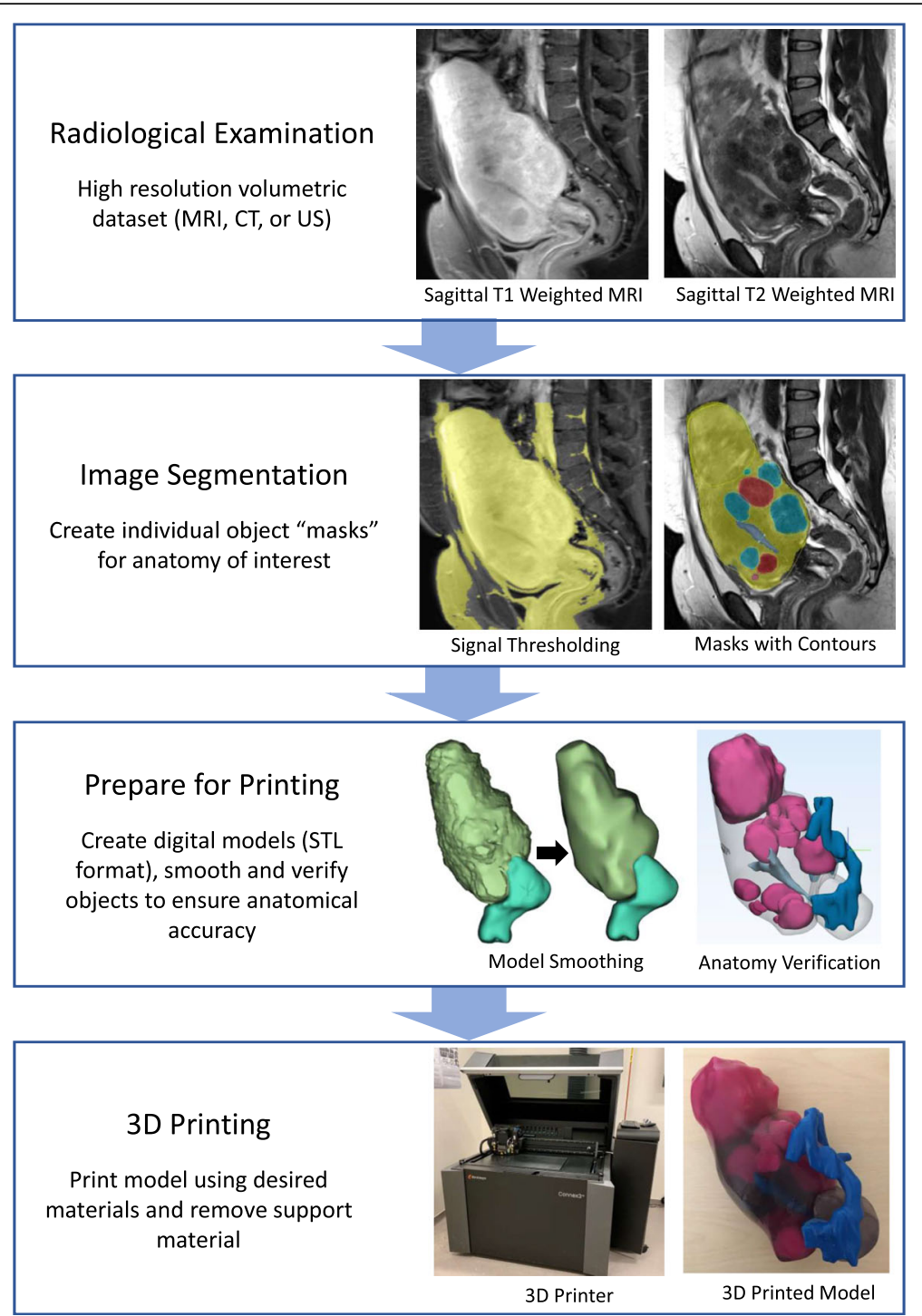

Fig. 1 General overview of 3D printing workflow with segmentation of MRI using images of a multi-fibroid uterus as an example

uterine model to identify the best location for incision during a caesarean delivery complicated by multiple fibroids [37].

\section{Endometriosis}

Endometriosis is a common gynecological disease which affects approximately $15 \%$ of females of reproductive age [38], causing symptoms such as, dysmenorrhea, dysuria, dyschezia, dyspareunia, chronic pelvic pain and infertility, which can have a significant impact on their quality of life [30], and a significant economic burden on our healthcare system $[39,40]$.

Surgery is a common approach for the diagnosis and treatment of endometriosis. Although best practice guidelines recommend a complete surgical excision of all endometriotic lesions in a single surgery, if possible
[41, 42], many endometriosis surgeries are incomplete or result in surgical complications because a surgeon may encounter more complex disease than expected. Incomplete and inadequate surgeries lead to persistent symptoms, repeat referral and/or repeat surgery, with more than $60 \%$ of patients undergoing multiple operations in an attempt to alleviate the symptoms of pain [43]. Furthermore, laparoscopic excision of deep endometriosis is known to be challenging, even in the hands of highly skilled and well-trained surgeons, as it is both technically demanding and long, with major and minor complications occurring in up to $10 \%$ of cases $[44,45]$.

A thorough understanding of patient-specific anatomy and the extent of the disease is required for developing an appropriate surgical plan. For example, endometriosis affecting the bowel can be surgically managed by 

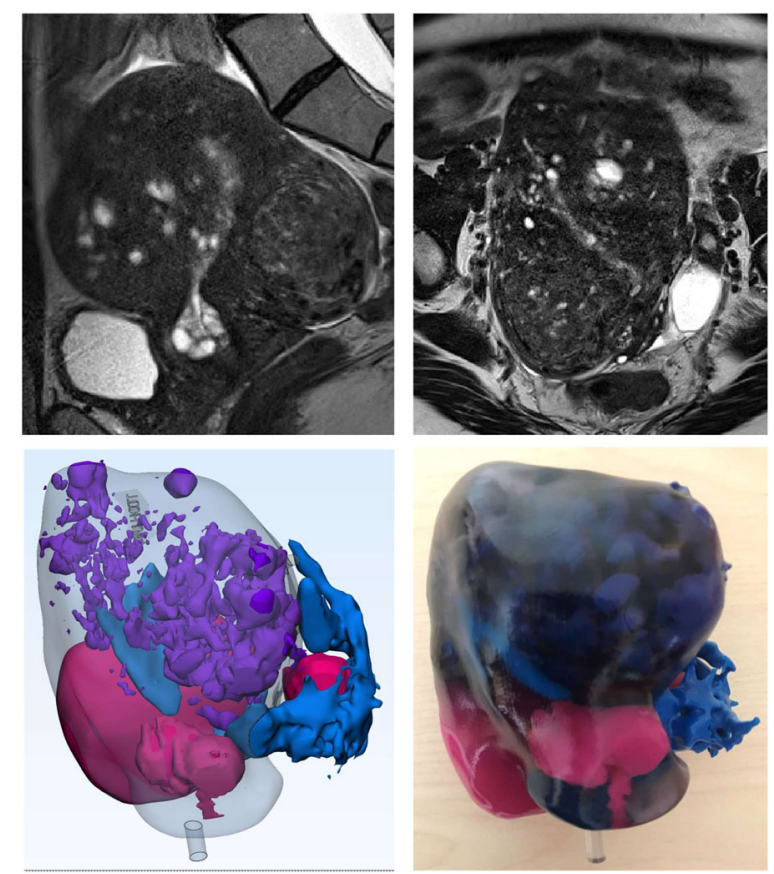

Fig. 2 Sagittal (top left) and axial (top right) view of fibroid uterus with adenomyosis depicted on MRI T2 images. MRI images were used to render a 3D digital model (bottom left) and printed as a physical 3D model (bottom right). Adenomyosis was printed in purple, fibroids in magenta, endometrium and external vasculature in blue, and non-neoplastic myometrium and cervical tissue in clear material

shaving, discoid resection, or segmental resection. The lesion(s) size, depth and location (i.e. distance from anal verge) will determine the approach required and if other surgical services need to be consulted [46-48]. However, much of this information is not fully appreciated by the surgeon until direct visualization.

Patient specific anatomical 3D printed models have the potential to improve a gynecologic surgeon's ability to prepare for highly complex surgical cases involving severe endometriosis. They may allow surgeons to better visualize patient-specific anatomy, the location and extent of endometriotic nodules, suspicion for intraoperative complications, and to optimize intra-operative performance, helping to maximize disease excision while minimizing surgical complications.

To our knowledge, only one other group has created a 3D model of endometriosis. Ajao et al. [49] retrospectively printed a patient-specific anatomical model of a rectovaginal endometriotic nodule from MRI images for a patient with history of endometriosis and persistent pain. Ajao et al. report that the model accurately demonstrated the location and structural relationship of the endometriotic nodule to surrounding structures [49].

Our group recently created a 3D model for complex endometriosis (Fig. 4). Here we show a case of bilateral

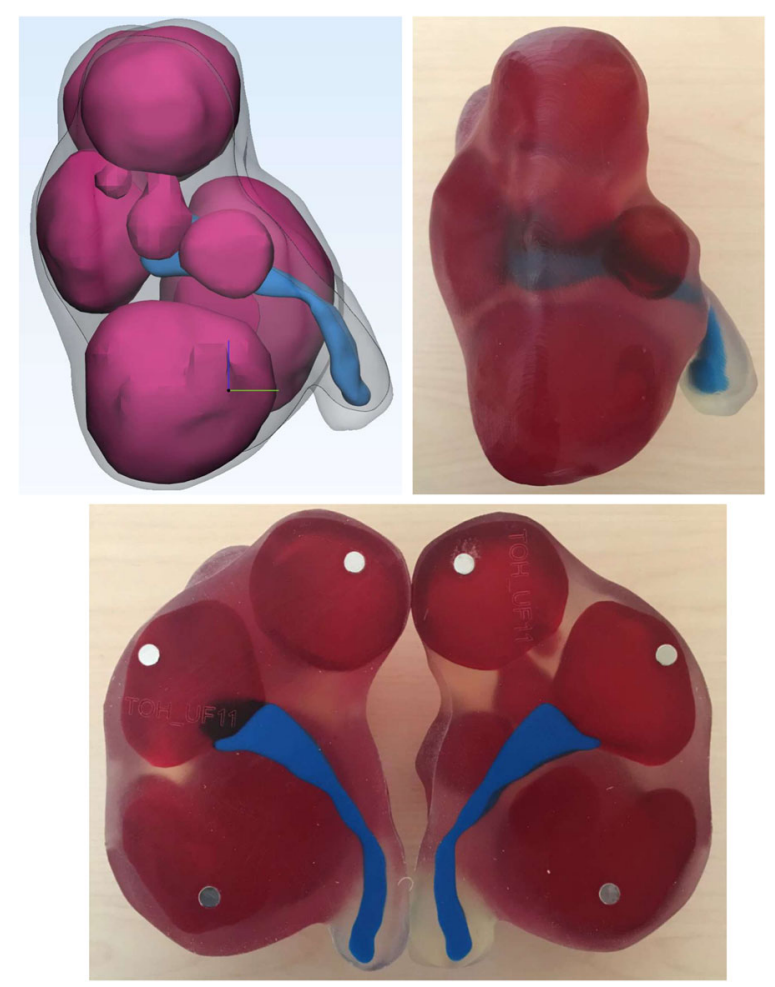

Fig. 3 Sagittal plane views of 3D digital model (top left) and 3D printed model (top right). The model was printed in two pieces (bottom), with the mid-sagittal plane as the dissecting line. This was done to improve visualisation of deep fibroids and their position relative to the endometrium. Fibroids were printed translucent red, endometrium in opaque blue, and non-neoplastic myometrium and cervical tissue in clear material. Magnets (grey dots) are used to hold the two pieces together

endometriomas tethered to the posterior uterus with "kissing ovaries" morphology. The bowel is displaced anteriorly, and the top of the bladder is distorted proximally. Pre-operative medical imaging indicated the bilateral endometriomas, and deep endometriosis between the rectum, uterus, and right ovary causing an obliterated cul-de-sac and bowel tethering to the uterosacral region (Fig. 5). The 3D model correlated with surgical presentation whereby severe adhesions of the bowel and bladder covered the uterine and ovarian structures so pelvic anatomy could not be visualized on initial inspection (Fig. 5). Of note was the close proximity of the left ureter to the left endometrioma reflected in both the model and during the surgery. Our experience with 3D models for cases of deep endometriosis supports observations by Ajao et al. [49]. We believe that 3D models for surgical cases of deep endometriosis can help optimize a surgeon's pre-surgical plan improving their ability to visualize complex anatomy. 

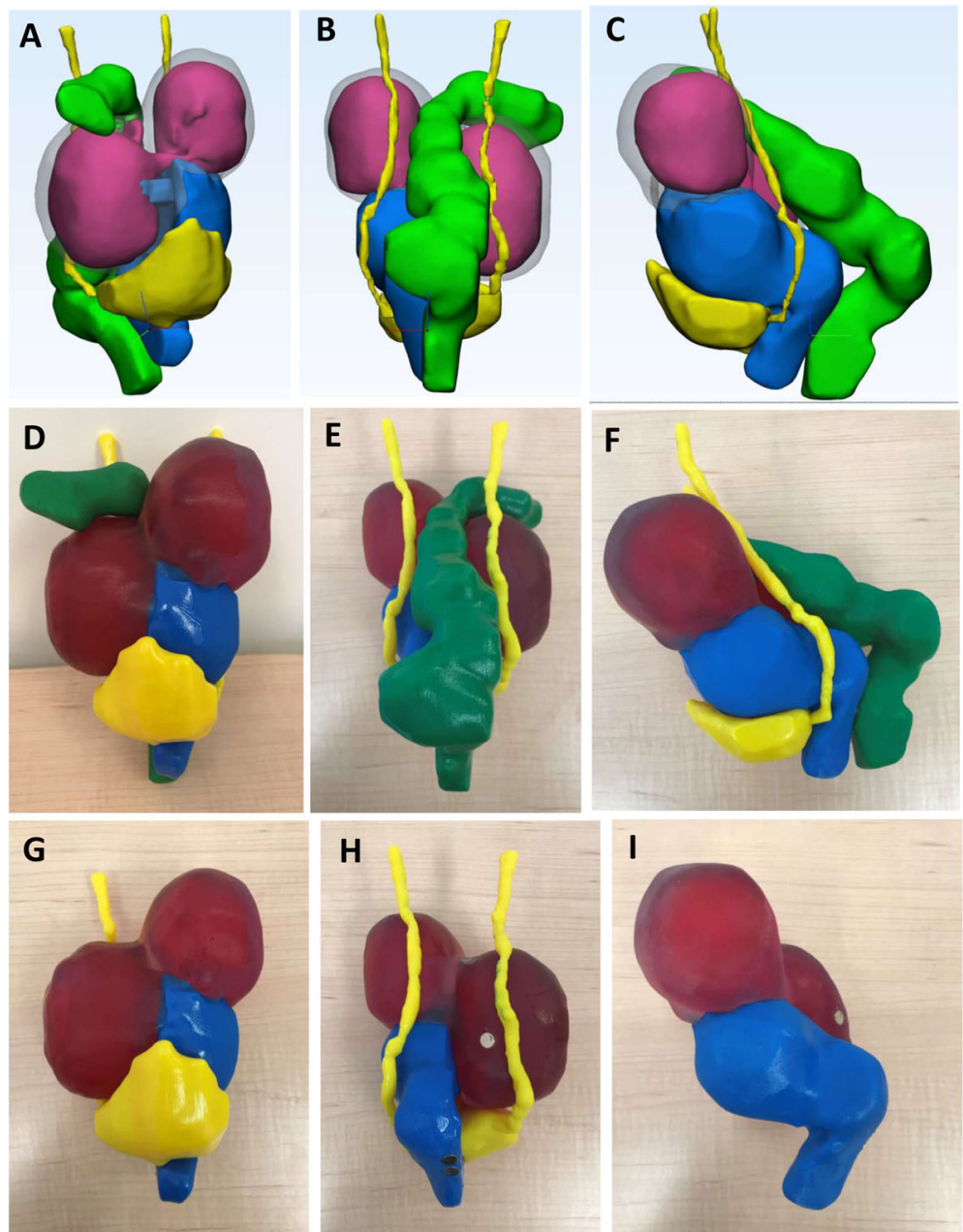

Fig. 4 3D digital model for case of deep endometriosis with $\mathbf{a}$ anterior, $\mathbf{b}$ posterior and $\mathbf{c}$ sagittal views. 3D printed model with $\mathbf{d}$ anterior, $\mathbf{e}$ posterior and $\mathbf{f}$ sagittal views. Bladder and ureters were printed in yellow; uterus cervix and vagina printed in blue; bowel and rectum printed in green; endometriomas printed in magenta and ovarian tissue printed in clear material. The model was printed so the bowel and the bladder + ureters could be removed. $\mathbf{g}$ and $\mathbf{h}$ show anterior and posterior views without the bowel; $\mathbf{i}$ is a sagittal view of just the uterus + cervix + vagina and endometriomas

\section{Barriers to clinical uptake}

Two major barriers for the incorporation of 3D models into clinical practice and standard of care are cost and time needed to create the models. Considering material alone, our gynecological models cost between $\$ 500.00$ and $\$ 1700.00$ CAD to create at $100 \%$ scale, with fibroid models being the most expensive due to enlarged uteri. Our models are comparable in cost to models of the heart with congenital abnormalities [50] and aortic aneurysms [51]. As technology evolves, the cost of 3D printers, supporting software and materials are expected to decrease. Based on our experience, cost-saving considerations can include printing models to $50 \%$ scale and printing structures of interest in opaque material (i.e. fibroids) with sparse infill parameters (i.e. internal scaffold).
The average time required to segment our models was approximately $4-6 \mathrm{~h}$ and 22 (range: $12-40$ ) h to print. This is comparable to other reports of $3 \mathrm{D}$ printing in gynecology [36, 49]. A major limitation contributing to large processing times is the inability to automatically segment gynecological anatomy. Automatic thresholding algorithms are good for segmenting structures with distinct contrast values such as bones and air cavities; though, for soft tissues, available automatic and semiautomatic algorithms are subpar at isolating the various tissue types from the surrounding structures. This is because other tissues within the capture volume have similar signal intensities to gynecological anatomy. An example of this limitation is shown in Fig. 1, left image of second box. Here we tried to isolate the uterine tissue using automatic signal thresholding but surrounding fat, 

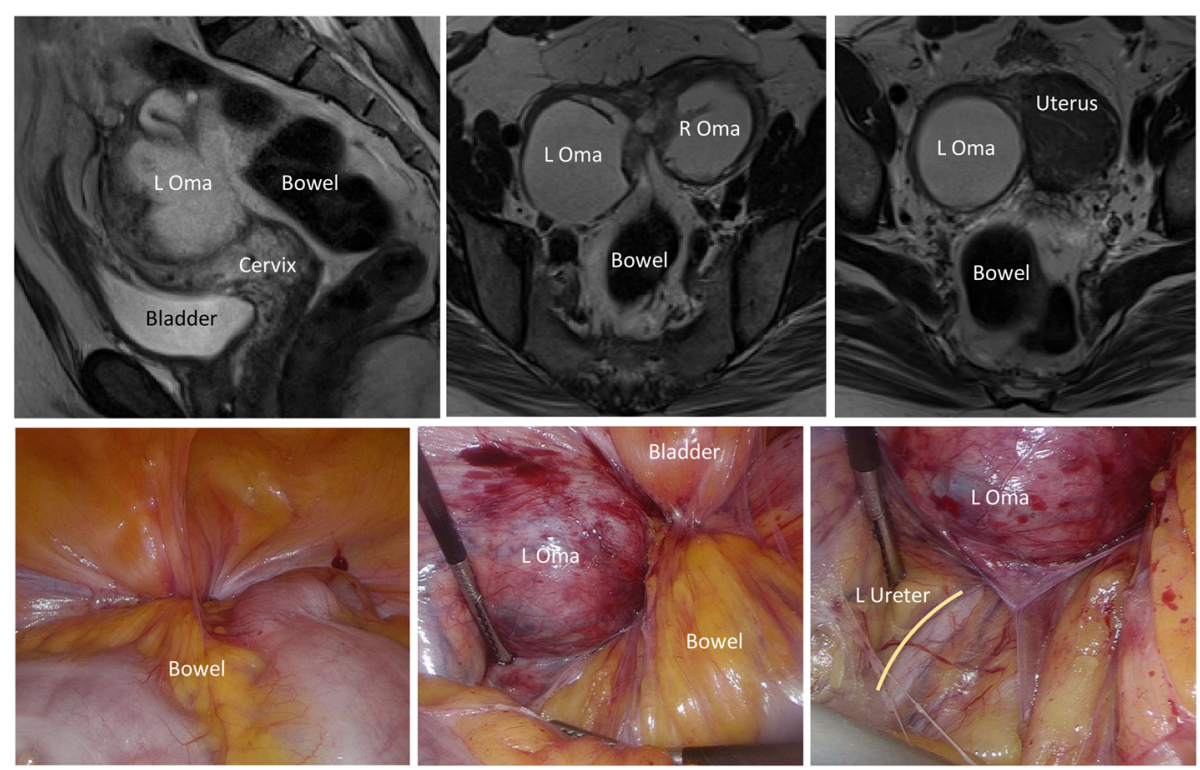

Fig. 5 Clinical photos correlating to model in Fig. 4. Sagittal view (top left) and axial views (top middle and top right) of MRI T2 images depicting bilateral endometriomas, distorted bladder, and retroflexion of the uterus' fundal region. Surgical presentation with no pelvic anatomy seen on initial inspection due to severity of adhesions of the bowel and bladder (bottom left), the bowel adhering to the left endometrioma and bladder (bottom middle), and the close proximity of the left ureter to the left endometrioma (bottom right)

bowel, fascia etc. are also included. Furthermore, differentiating uterine pathologies can be challenging since lesions can present on a spectrum of hypoechoic to hyperechoic relative to the surrounding myometrium $[52,53]$. As such, manual corrections are needed to ensure segmentation accuracy which increases processing times and indirectly inflates the cost of 3D gynecological models. In light of this major limitation, recent works have shown promise using deep learning and machinelearning techniques for multi-organ medical image segmentation and medical diagnosis [54, 55]. However, there is a need for high-quality datasets to optimize these algorithms for future application in a clinical setting.

Despite these current limitations, a recent cost-savings analysis by Ballard et al. [56] demonstrated a $60 \mathrm{~min}$ mean decrease in surgical time when 3D printed models were used for pre-operative planning or intra-operative surgical guides in orthopaedics or maxillofacial surgery. This decrease in operating time translated to a mean savings of $\$ 3720$ USD per case. The clinical benefits of reduced operating time and surgical accuracy in a systematic review by Diment et al. [22]. As such, we believe the overall cost of labour, equipment and materials may be balanced by the clinical benefits and reduced burden on the system. Future work on the benefits of 3D printed models in gynecologic surgery should include a cost-effectiveness analysis to demonstrate potential financial benefit of using 3D printed models for reducing operating times and improving patient outcomes on our healthcare system.

\section{Future directions of 3D printing in gynecology}

We see 3D printed models as a novel tool for the preparation and planning of complex surgical procedures, hence having utility which may extend to multiple obstetrical and gynecologic surgeries. For example, several studies have demonstrated the benefit of a multidisciplinary approach involving extensive surgical planning for the optimization of surgical outcomes in cases of placenta accreta spectrum [57, 58]. As such, 3D printed models, which has the potential to improve visualization of maternal, placental and fetal anatomy, may assist in the development of the most appropriate multidisciplinary surgical team, who together can establish a surgical approach which will minimize both maternal and neonatal morbidity and mortality. Additionally, we foresee uses of 3D printing in surgical planning for urogynecology procedures to maximize efficacy and reduce complications of surgeries aimed at treating pelvic floor disorders, and for extensive gynecologic oncology surgeries.

Further applications of 3D printed models in gynecology includes patient education. It is crucial that patients feel a strong understanding of their pathology and plan of care. However, it can be difficult for patients to comprehend complex medical terminology, and 2D radiologic images, which may be provided by their 
surgeon when they are being counselled in preparation for gynecologic surgery. Aluwee and colleagues [36] created 3D models in preparation for hysterectomy in five patients diagnosed with uterine endometrial cancer and through a questionnaire-based study they showed utility of 3D printed models for both patient education and surgical planning. They reported that patients were satisfied with the uterine 3D models for their understanding of the disease, surgical procedures, and risk of complications. In addition, the surgeons described a favourable experience, reporting that the models facilitated preoperative explanation of surgery to patients and helped obtain information on the positional relationship between the uterus and the tumor [36].

Further, 3D printed models may also benefit surgical trainees, including medical students, residents, and fellows. Within the operating room, surgeons must balance their time spent teaching learners with optimizing patient care and achieving surgical efficiency. Hence, medical educators are constantly in search of strategies and tools to help with teaching surgical trainees. 3D images and models have been used for helping trainees to learn and understand patient specific anatomy for their own surgical planning purposes [59-62]. Additionally, using tissue similar materials, 3D models may be used in simulation-based training, to allow gynecologic procedures to be taught, learned, and practiced outside of the operating room setting.

\section{Conclusion}

To minimize the risk of surgical complications and offer the best health outcomes to patients, successful gynecologic surgery requires a thorough understanding of the patient's anatomy and burden of disease. A surgeon's ability to develop a well-thought-out surgical plan is essential to optimizing their intra-operative performance. The adage "most surgery is done in your head" is the motivation behind developing a 3D tool, which has the potential to help the surgeon to mentally rehearse their surgical approach, the planes of dissection, maneuverability, and visibility before making an incision.

We have outlined the utility of 3D printing for surgical planning in gynecology, through two specific examples, uterine fibroids and endometriosis. We also provided a $3 \mathrm{D}$ printing protocol to encourage ongoing research and use of 3D printing for this purpose. Further, we have described multiple additional applications of 3D printing in gynecology, outlining the potential unique multi-faceted role $3 \mathrm{D}$ printing may have in the specialty in the future.

\section{Acknowledgements}

The authors would like to thank Drs. Kristina Arendas, Innie Chen, and Karine Lortie of the Ottawa Hospital Minimally Invasive Gynecology group and Drs. Waleed Althobaity, Leonid Chepelev, Matthew McInnes, and Shauna
Diugenan from The Ottawa Hospital's Department of Diagnostic Imaging in their contributions to our 3D printing for gynecology research program.

\section{Contribution to authorship}

All authors were involved in the conceptualization, data collection, writing, and final draft review of this article. The author(s) read and approved the final manuscript.

\section{Funding}

This work was supported by the The Ottawa Hospital 3D Printing Lab and The Ottawa Hospital Minimally Invasive Gynecology Research Group.

Availability of data and materials

Not applicable.

\section{Declarations}

\section{Ethics approval}

This work was exempt from the Ottawa Health Science Network Research Ethics Board review.

\section{Consent for publication}

Consent to publish patient images was obtained.

\section{Competing interests}

The authors declare that they have no conflicts of interest related to the work presented. S.S. reports grants and personal fees from Bayer, Abbvie, and Cooper Surgical, outside the submitted work.

\section{Author details}

'Department of Clinical Epidemiology, Ottawa Hospital Research Institute, 1967 Riverside Dr, 7th Floor, Ottawa, ON K1H7W9, Canada. ${ }^{2}$ Department of Obstetrics and Gynecology, Faculty of Medicine, University of Ottawa, Ottawa, ON, Canada. ${ }^{3}$ Department of Medical Imaging, The Ottawa Hospital, Ottawa, ON, Canada. ${ }^{4}$ Department of Radiology, Faculty of Medicine, University of Ottawa, Ottawa, ON, Canada. ${ }^{5}$ Department of Obstetrics, Gynecology and Newborn Care, The Ottawa Hospital, Ottawa, ON, Canada.

Received: 20 May 2021 Accepted: 10 June 2021

Published online: 05 July 2021

\section{References}

1. Stewart E. Clinical practice. Uterine fibroids. N Engl J Med. 2015;372(17): 1646-55.

2. Tan N, Margolis DJ, McClure TD, Thomas A, Finley DS, Reiter RE, et al. Radical prostatectomy: value of prostate MRI in surgical planning. Abdom Imaging. 2012;37(4):664-74.

3. Fan XC, Nemoto T, Blatto K, Mangiafesto E, Sundberg J, Chen A, et al. Impact of presurgical breast magnetic resonance imaging (MRI) on surgical planning - a retrospective analysis from a private radiology group. Breast J. 2013;19(2):134-41.

4. Preece D, Williams SB, Lam R, Weller R. "Let's get physical": advantages of a physical model over 3D computer models and textbooks in learning imaging anatomy. Anat Sci Educ. 2013;6(4):216-24.

5. Yaman C, Jesacher K, Polz W. Accuracy of three-dimensional transvaginal ultrasound in uterus volume measurements; comparison with twodimensional ultrasound. Ultrasound Med Biol. 2003;29(12):1681-4.

6. Flaxman TE, Singh SS, Morissette C, Della Zazzera V. Three-dimensional ultrasound imaging of deep infiltrating endometriotic lesions of the bowel. J Minim Invasive Gynecol. 2017;25(5):753-4.

7. Aluwee SA, Kato H, Zhou X, Hara T, Fujita H, Kanematsu M, et al. Magnetic resonance imaging of uterine fibroids: a preliminary investigation into the usefulness of 3D-rendered images for surgical planning. Springerplus. 2015; 4:384.

8. Mitsouras D, Liacouras P, Imanzadeh A, Giannopoulos AA, Cai T, Kumamaru KK, et al. Medical 3D printing for the radiologist. Radiographics. 2015;35(7): 1965-88.

9. Mitsouras D, Liacouras PC, Wake N, Rybicki FJ. RadioGraphics update: medical 3D printing for the radiologist. Radiographics. 2020;40(4):E21-3.

10. Marconi S, Pugliese L, Botti M, Peri A, Cavazzi E, Latteri S, et al. Value of 3D printing for the comprehension of surgical anatomy. Surg Endosc. 2017; 
31(10):4102-10. https://doi.org/10.1007/s00464-00017-05457-00465 Epub 02017 Mar 00469.

11. Smelt JLC, Suri T, Valencia O, Jahangiri M, Rhode K, Nair A, et al. Operative planning in thoracic surgery: a pilot study comparing imaging techniques and three-dimensional printing. Ann Thorac Surg. 2019;107(2):401-6. https://doi.org/10.1016/j.athoracsur.2018.1008.1052 Epub 2018 Oct 1011

12. Chen C, Cai L, Zheng W, Wang J, Guo X, Chen H. The efficacy of using 3D printing models in the treatment of fractures: a randomised clinical trial. BMC Musculoskelet Disord. 2019;20(1):65. https://doi.org/10.1186/s12891-12 019-12448-12899.

13. Punyaratabandhu T, Liacouras $P C$, Pairojboriboon S. Using $3 D$ models in orthopedic oncology: presenting personalized advantages in surgical planning and intraoperative outcomes. 3D Print Med. 2018;4(1):12. https:// doi.org/10.1186/s41205-41018-40035-41206.

14. Corona PS, Vicente M, Tetsworth K, Glatt V. Preliminary results using patientspecific 3d printed models to improve preoperative planning for correction of post-traumatic tibial deformities with circular frames. Injury. 2018; 49(Suppl 2):S51-9. https://doi.org/10.1016/j.injury.2018.1007.1017.

15. Vaishya R, Patralekh MK, Vaish A, Agarwal AK, Vijay V. Publication trends and knowledge mapping in 3D printing in orthopaedics. J Clin Orthopaed Trauma. 2018;9(3):194-201.

16. Byrne N, Velasco Forte M, Tandon A, Valverde I, Hussain T. A systematic review of image segmentation methodology, used in the additive manufacture of patient-specific 3D printed models of the cardiovascular system. JRSM Cardiovasc Dis. 2016;5:204800401664546.

17. El Sabbagh A, Eleid M, Al-Hiji M, Anavekar NS, Holmes DR, Nkomo VT, et al. The various applications of 3D printing in cardiovascular diseases. Curr Cardiol Rep. 2018;20(6):47.

18. Randazzo M, Pisapia JM, Singh N, Thawani JP. 3D printing in neurosurgery: a systematic review. Surg Neurol Int. 2016;7(Suppl 33):S801-9.

19. Barbosa MZ, Zylbersztejn DS, de Mattos LA, Carvalho LF. Threedimensionally-printed models in reproductive surgery: systematic review and clinical applications. Minerva Ginecol. 2019;71(3).

20. Berman B. 3-D printing: the new industrial revolution. Bus Horizons. 2012; 55(2):155-62.

21. Michalski MH, Ross JS. The shape of things to come: 3D printing in medicine. JAMA. 2014;312(21):2213-4.

22. Diment LE, Thompson MS, Bergmann JHM. Clinical efficacy and effectiveness of 3D printing: a systematic review. BMJ Open. 2017;7(12): e016891.

23. Schubert $C$, van Langeveld MC, Donoso LA. Innovations in 3D printing: a 3D overview from optics to organs. Br J Ophthalmol. 2014;98(2):159-61.

24. Herrmann MD, Clunie DA, Fedorov A, Doyle SW, Pieper S, Klepeis V, et al. Implementing the DICOM standard for digital pathology. J Pathol Inform. 2018;9:37.

25. Stewart EA. Uterine fibroids. N Engl J Med. 2015;372:1646-55.

26. Zimmermann A, Bernuit D, Gerlinger C, Schaefers M, Geppert K. Prevalence, symptoms and management of uterine fibroids: an international internetbased survey of 21,746 women. BMC Womens Health. 2012;12:6.

27. Catherino WH, Parrott E, Segars J. Proceedings from the National Institute of Child Health and Human Development Conference on the Uterine Fibroid Research Update Workshop. Fertil Steril. 2011;95:9-12.

28. Okolo S. Incidence, aetiology and epidemiology of uterine fibroids. Best Pract Res Clin Obstet Gynaecol. 2008:22:571-88.

29. Bulun SE. Uterine fibroids. N Engl J Med. 2013;369:1344-55.

30. Nisenblat V, Prentice L, Bossuyt PMM, Farquhar C, Hull ML, Johnson N. Combination of the non-invasive tests for the diagnosis of endometriosis. Cochrane Database Syst Rev. 2016:7(7):CD012281.

31. Sizzi O, Rossetti A, Malzoni M, Minelli L, La Grotta F, Soranna L, et al. Italian multicenter study on complications of laparoscopic myomectomy. J Minim Invasive Gynecol. 2007;14(4):453-62.

32. Learman LA, Summitt RL, Varner RE, McNeeley SG, Goodman-Gruen D, Richter $\mathrm{HE}$, et al. A randomized comparison of total or supracervical hysterectomy: surgical complications and clinical outcomes. Obstet Gynecol. 2003;102:453-62.

33. Seinera P, Arisio R, Decko A, Farina C, Crana F. Laparoscopic myomectomy: indications, surgical technique and complications. Hum Reprod (Oxford, England). 1997;12:1927-30.

34. Flaxman T, Sheikh A, Althobaity W, Miguel O, Cooke C, Singh S. Optimizing pre-surgical planning for a complex myomectomy using a patient-specific three-dimensional printed anatomical model. J Obstet Gynaecol Can. 2019; 42(6):697-9.

35. Cooke CM, Flaxman T, Sheikh A, Althobaity W, Miguel O, Singh SS. 3D printing in gynecologic surgery -an innovative tool for surgical planning. J Minim Invasive Gynecol. 2019;26(7):S19-20.

36. Aluwee SS, Zhou X, Kato H, Makino H, Muramatsu C, Hara T, et al. Evaluation of pre-surgical models for uterine surgery by use of three-dimensional printing and mold casting. Radiol Phys Technol. 2017;10(3):279-85.

37. Mackey A, Ng Jl, Core J, Nguyen L, Cross D, Lim P, et al. Three-dimensionalprinted uterine model for surgical planning of a cesarean delivery complicated by multiple myomas. Obstet Gynecol. 2019;133(4).

38. Wheeler JM. Epidemiology of endometriosis-associated infertility. J Reprod Med. 1989;34(1):41-6.

39. Brosens I, Benagiano G. Endometriosis, a modern syndrome. Indian J Med Res. 2011;133:581-93.

40. Levy AR, Osenenko KM, Lozano-Ortega G, Sambrook R, Jeddi M, Belisle S, et al. Economic burden of surgically confirmed endometriosis in Canada. Obstet Gynaecol Can. 2011;33(8):830-7. https://doi.org/10.1016/S1701-2163 (1016)34986-34986.

41. Kennedy S, Bergqvist A, Chapron C, D'Hooghe T, Dunselman G, Greb R, et al. ESHRE guideline for the diagnosis and treatment of endometriosis. Hum Reprod. 2005;20(10):2698-704. https://doi.org/10.1093/humrep/dei2135 Epub 2005 Jun 2624

42. Abrao MS, Petraglia F, Falcone T, Keckstein J, Osuga Y, Chapron C. Deep endometriosis infiltrating the recto-sigmoid: critical factors to consider before management. Hum Reprod Update. 2015;21(3):329-39. https://doi. org/10.1093/humupd/dmv1003 Epub 2015 Jan 1024.

43. Saraswat L, Ayansina D, Cooper KG, Bhattacharya S, Horne AW, Bhattacharya S. Impact of endometriosis on risk of further gynaecological surgery and cancer: a national cohort study. BJOG Int J Obstet Gynaecol. 2018;125(1):6472 .

44. Slack A, Child T, Lindsey I, Kennedy S, Cunningham C, Mortensen N, et al. Urological and colorectal complications following surgery for rectovaginal endometriosis. BJOG. 2007;114(10):1278-82. https://doi.org/10.1111/j.14710528.2007.01477.x

45. Ruffo G, Scopelliti F, Scioscia M, Ceccaroni M, Mainardi P, Minelli L. Laparoscopic colorectal resection for deep infiltrating endometriosis: analysis of 436 cases. Surg Endosc. 2010;24(1):63-7. https://doi.org/10.1007/ s00464-00009-00517-00460 Epub 2009 May 00423.

46. Oliveira MAP, Pereira TRD, Gilbert A, Tulandi T, de Oliveira HC, De Wilde RL. Bowel complications in endometriosis surgery. Best Pract Res Clin Obstet Gynaecol. 2016;35:51-62

47. Phitayakorn R, Delaney CP, Reynolds HL, Champagne BJ, Heriot AG, Neary P, et al. Standardized algorithms for management of anastomotic leaks and related abdominal and pelvic abscesses after colorectal surgery. World 」 Surg. 2008;32:1147-56.

48. Donnez O, Roman $\mathrm{H}$. Choosing the right surgical technique for deep endometriosis: shaving, disc excision, or bowel resection? Fertil Steril. 2017; 108:931-42.

49. Ajao MO, Clark NV, Kelil T, Cohen SL, Einarsson Jl. Case report: Threedimensional printed model for deep infiltrating endometriosis. J Minim Invasive Gynecol. 2017;24(7):1239-42.

50. Mottl-Link S, Hübler M, Kühne T, Rietdorf U, Krueger JJ, Schnackenburg B, et al. Physical models aiding in complex congenital heart surgery. Ann Thorac Surg. 2008:86(1):273-7.

51. Håkansson A, Rantatalo M, Hansen T, Wanhainen A. Patient specific biomodel of the whole aorta-the importance of calcified plaque removal. VASA. Zeitschrift fur Gefasskrankheiten. 2011;40(6):453-9.

52. Wilde S, Scott-Barrett S. Radiological appearances of uterine fibroids. Indian J Radiol Imaging. 2009;19:222-31.

53. Shwayder J, Sakhel K. Imaging for uterine myomas and adenomyosis. J Minim Invasive Gynecol. 2014:21:362-76.

54. Kamnitsas K, Ledig C, Newcombe VFJ, Simpson JP, Kane AD, Menon DK, et al. Efficient multi-scale 3D CNN with fully connected CRF for accurate brain lesion segmentation. Med Image Anal. 2017;36:61-78.

55. Lundervold AS, Lundervold A. An overview of deep learning in medical imaging focusing on MRI. Z Med Phys. 2019;29(2):102-27.

56. Ballard DH, Mills P, Duszak R, Weisman JA, Rybicki FJ, Woodard PK. Medical 3D printing cost-savings in orthopedic and maxillofacial surgery: cost analysis of operating room time saved with 3D printed anatomic models and surgical guides. Acad Radiol. 2019;27(8):1103-13. 
57. Eller AG, Bennett MA, Sharshiner M, Masheter C, Soisson AP, Dodson M, et al. Maternal morbidity in cases of placenta accreta managed by a multidisciplinary care team compared with standard obstetric care. Obstet Gynecol. 2011;117(2):331-7.

58. Shamshirsaz AA, Fox KA, Salmanian B, Diaz-Arrastia CR, Lee W, Baker BW, et al. Maternal morbidity in patients with morbidly adherent placenta treated with and without a standardized multidisciplinary approach. Am J Obstet Gynecol. 2015;212(2):218.e211-9.

59. Lau I, Sun Z. Three-dimensional printing in congenital heart disease: a systematic review. J Med Radiat Sci. 2018.

60. Kim JW, Lee Y, Seo J, Park JH, Seo YM, Kim SS, et al. Clinical experience with three-dimensional printing techniques in orthopedic trauma. J Orthop Sci. 2018.

61. Silberstein JL, Maddox MM, Dorsey P, Feibus A, Thomas R, Lee BR. Physical models of renal malignancies using standard cross-sectional imaging and 3dimensional printers: a pilot study. Urology. 2014;84(2):268-72.

62. Dong M, Chen G, Qin K, Ding X, Zhou D, Peng C, et al. Development of three-dimensional brain arteriovenous malformation model for patient communication and young neurosurgeon education. Br J Neurosurg. 2018: $1-4$

\section{Publisher's Note}

Springer Nature remains neutral with regard to jurisdictional claims in published maps and institutional affiliations.

Ready to submit your research? Choose BMC and benefit from:

- fast, convenient online submission

- thorough peer review by experienced researchers in your field

- rapid publication on acceptance

- support for research data, including large and complex data types

- gold Open Access which fosters wider collaboration and increased citations

- maximum visibility for your research: over $100 \mathrm{M}$ website views per year

At BMC, research is always in progress.

Learn more biomedcentral.com/submissions 